\title{
NOTAS
}

\section{El sentido del don}

\section{Manuel López Casquete de Prado'}

Resumen: La nota presente una reflexión sobre el concepto del don en relación con los de reciprocidad y de gratuidad, desde una perspectiva antropológica, sin descuidar la dimensión social. El autor pone en relación la lógica del don ("dar desde la reciprocidad») con la corriente italiana de la "Economía civil", así como con la reflexión ética desde la «razón cordial», que en última instancia se refiera también a la precepción de la alteridad como don, reflexión presenta en el pensamiento social cristiano reciente, como es el caso de la encíclica de Papa Ratzinger Caritas in veritate. La nota concluye vinculando la lógica del don con la obligación sentida y querida por la persona.

Palabras clave: Don (lógica del), economía civil, razón cordial, reciprocidad.

Fecha de recepción: 26 de junio de 2015.

Fecha de admisión definitiva: 16 de septiembre de 2015.

\section{The meaning of the don}

Abstract: A reflection on the concept of the gift on the reciprocity and free, from an anthropological perspective, the present note without neglecting the social dimension. The author puts in relation the logic of the gift ("give from reciprocity") the Italian "Civil economy" current, as well as the ethical from

\section{La signification du don}

Résumé: La note présente une réflexion sur le concept du don dans le cadre de la réciprocité et de la gratuité, du point de vue anthropologique, sans pour autant négliger sa dimension sociale. L'auteur rapporte la logique du don («donner de la réciprocité») avec le courant «économie civile» de l'Italie et

\footnotetext{
' Departamento de Humanidades y Filosofía. Universidad Loyola Andalucía.
} 
the cordial "reason" reflection, that ultimately it refers also to the perception of otherness as don, reflection in the Christian social thought recent, as in the case of the Encyclical of Pope Ratzinger Caritas in veritate. The note concludes by linking the logic of the gift with one obligation felt and loved by the person.

Key-words: Don (logic of the), civilian economy, friendly reason, reciprocity. de la réflexion éthique de la «raison cordiale, qui a finalement se référe également à la precepción de l'altérité comme un don, une réflexion présenté lors de la récente pensée sociale chrétienne, comme l'encyclique du pape Ratzinger Caritas in Veritate. La note conclut en reliant la logique du don avec celle d'une obligation sentie face a la personne chère.

Mots clé: Don (logique du), économie civile, raison cordiale, réciprocité.

El filósofo Martin Heidegger, en un bellísimo texto titulado Serenidad (Gelassenheit), distingue entre dos posibles modos de utilizar el pensamiento: el uso meditativo y el uso calculador. Según Heidegger, el pensamiento calculador busca combinar los datos existentes de modo que pueda maximizar el resultado en términos de beneficio o utilidad. En cambio, el pensamiento meditativo intenta abrir al ser humano al horizonte del sentido: el de nuestra actividad, el de nuestra vida, el de nuestro paso por la existencia. Lo que pretendemos en esta comunicación es, justamente, preguntarnos cuál es el sentido profundo del don (en línea con ese segundo uso del pensamiento, según la caracterización de Heidegger) y por qué la gratuidad puede desvelarnos algunas de las más genuinas claves del horizonte de desarrollo humano integral (como decía el inolvidable Jacques Maritain).

Siguiendo con el planteamiento de Heidegger, sólo desde un uso meditativo del pensamiento, que indague en el sentido profundo del don, podremos entender su lógica; por tanto, mi primer propósito es el de escapar aquí de la dialéctica del pensamiento calculador. Esto puede parecer algo obvio ya que, por definición, es imposible entender el don desde la lógica utilitarista del coste-beneficio. Y sin embargo conviene decirlo, porque con frecuencia se ha intentado plantear que la lógica del don es adecuada para conseguir determinados efectos desde el punto de vista del pensamiento calculador. Así, determinados enfoques de RSE plantean que una empresa que se abre al don y a la gratuidad en su ámbito de actividad puede conseguir réditos en su imagen social, lo que tendrá efectos directos en la cuenta de pérdidas y ganancias. Aunque es cierto que, a veces, pueden derivarse efectos positivos desde el punto de vista de la utilidad, es total y absolutamente imposible entender la lógica del don desde este tipo de pensamiento. Y ello por la sencilla razón de que, hablar de don y beneficio, es un oxímoron, una contradic- 
ción en los términos. Sólo hay don si no se espera beneficio, si hay gratuidad. En la obra Economia civile22, Luigino Bruni y Stefano Zamagni plantean que hay tres posibles modos de dar en sociedad:

- Dar para recibir algo a cambio (contrato).

- Dar por obligación (sistema fiscal).

- Dar desde la reciprocidad (don).

Cuando esperamos beneficios, no existe la lógica del don, sino la del contrato. Cuando damos por obligación, tampoco existe don, sino obediencia a un precepto legal. De lo anterior se desprenden las dos características esenciales del don: la ausencia de contraprestación y su carácter libre.

Respecto a la ausencia de contraprestación, debemos hacer alguna matización, ya que la lógica de la reciprocidad encaja con la del don. Sin embargo, la reciprocidad propia del don no espera que el donatario nos restituya lo donado, sino que éste, a su vez, pueda donar, sea al donante o a cualquier otro (transitividad), y sin esperar que el valor económico de lo que dona sea equivalente al valor de lo que recibió. Un bellísimo ejemplo de esto es algo que sucedía con frecuencia en época medieval, cuando personas acaudaladas hacían donaciones económicas a cambio de oraciones. La belleza de este ejemplo estriba en que ambas personas (quien hacía la donación económica y quien hacía la de sus oraciones) estaban donando. Obviamente, cada una de ellas dona en la medida de sus posibilidades; pero esta reciprocidad convierte a los dos polos en donantes y receptores, los iguala en dignidad, ya que ambos tienen algo que ofrecer, y abre las puertas a una relación justa, entre iguales, posibilitadora de auténtica amistad cívica.

Por ese motivo, el don es radicalmente distinto a la limosna, en la que no hay reciprocidad, sino sólo una persona que da y otra que recibe; por ejemplo, en el capitalismo filantrópico estadounidense, hay una entidad que ofrece una limosna (habitualmente fundaciones) y personas necesitadas que la reciben. Este sistema, que implica la negación de la reciprocidad, transmite al donatario la idea de que él sólo puede recibir, porque no tiene nada que ofrecer; $y$ quien no tiene nada que ofrecer queda irremisiblemente condenado a la irrelevancia social. Esto es algo que nuestros sistemas sociales no deben permitir. En cambio, la lógica recíproca del don dignifica a quien dona y a quien recibe, porque también el donatario se

2 BrUNI, L. y ZAMAGNI, S. (2004), Economia civile, Bolonia, II Mulino. 
convierte a su vez en donante. Esta es la lógica transitiva de la reciprocidad. Por lo tanto, y como primera observación, es preciso remarcar que don es igual a dar sin esperar recibir.

La segunda cuestión, dado por sentado lo anterior, es que nos preguntemos cuál es el motivo del don, qué nos impulsa a dar sin esperar recibir. Parece obvio que, si no esperamos una contraprestación equivalente, sólo cabe una respuesta a esta pregunta: damos porque nos importa la suerte del otro; porque sentimos que lo que sucede al otro, en cierto modo, nos sucede también a nosotros. Esta es, a mi modo de ver, la clave de comprensión de la lógica del don. Para ilustrar esto daré un contraejemplo y tres ejemplos:

El contraejemplo aparece en Génesis 4:9. En ese versículo, Dios pregunta a Caín: "¿Dónde está tu hermano Abele". Todos conocemos la respuesta de Caín: "¿Por ventura soy yo guardián de mi hermano?". Quien responde, como Caín, que no es responsable de la suerte de su hermano, es incapaz de entender el sentido del don, ya que sólo nos sentimos inclinados a dar cuando nos hacemos responsables de lo que suceda al otro, al que consideramos no sólo digno, sino además "carne de nuestra carne".

¿Cuáles son, en cambio, los ejemplos que pueden ilustrar el sentido del don?

El primer ejemplo que quisiera exponer proviene de uno de los libros de la Ética a Nicómaco de Aristóteles. Es bien conocido que Aristóteles plantea que cada persona, si quiere ser feliz, debe observar un comportamiento virtuoso que se sitúa en el punto medio entre dos extremos. Así, la valentía está tan lejos de la cobardía como de la temeridad. Cuando Aristóteles se refiere a la virtud en el uso de los bienes (libro III), podríamos pensar que buscaría un término medio entre dar y retener los bienes, escapando tanto de la avaricia como de la prodigalidad. Efectivamente, Aristóteles escapa de estos extremos, pero plantea que el término medio en el uso de los bienes es la generosidad, ya que los bienes están para ser compartidos. El hombre virtuoso, según Aristóteles, es aquel que es generoso en el dar, sin incurrir en la prodigalidad. Lo que llama la atención de este planteamiento es que, para Aristóteles, es connatural al desarrollo de las capacidades íntimamente humanas y a nuestra posibilidad de ser felices la virtud de la generosidad. Con otras palabras, necesitamos de la gratuidad para poder desarrollarnos como personas. Volveremos sobre esto un poco más adelante. 
En un segundo ejemplo, me parece oportuno recordar una reflexión de Adela Cortina contenida en su Ética de la razón cordial: ${ }^{3}$

Sin duda, "obligación" es prácticamente un sinónimo de "deber" en todas las lenguas. Pero, si se piensa un poco, tiene una importante peculiaridad, y es que lo debido descansa en el reconocimiento de un vínculo, de una "ligatio", de la que se sigue una "ob-ligatio", y entonces la obligación puede ser o bien un deber, es decir, la respuesta a una exigencia, o bien el regalo que hace quien se sabe y siente ligado a otro. Sin ese reconocimiento del vínculo, el deber o el regalo carecen de sentido.

Sin ese reconocimiento del otro, sin hacer la experiencia de la dignidad del otro, sin asumir como tarea propia el reconocimiento de la dignidad del otro, es imposible entender el sentido del don, porque sólo podemos donar si miramos al otro a los ojos, si lo reconocemos, si lo sentimos como carne de nuestra propia carne y huesos de nuestros propios huesos. Sólo quien hace la experiencia del reconocimiento cordial del otro puede sentirse impulsado a dar desde la gratuidad.

Un tercer ejemplo es el aportado por Jacques Maritain, maestro de Pablo VI-según confesión del propio Papa- ${ }^{4}$ y uno de los inspiradores de Populorum Progressio (1967). Maritain basa todo su sistema en una importante distinción antropológica de raíz tomista: individuo - persona. Ser individuo es simplemente formar parte de un colectivo mayor, y remite a las dimensiones más materiales y periféricas del ser humano. En cambio, el concepto de persona no remite a ningún grupo, sino a la dignidad de nuestra condición humana que debe ser entendida como un fin en sí misma (la inspiración kantiana parece aquí clara). Toda estructura social, política y económica debe, en consecuencia, ponerse al servicio de los fines últimos de la persona. Según el filósofo parisino, la tarea de la educación es la de hacer crecer a la persona y disminuir al individuo. Y sólo hay un camino para ello: el amor, que se expresa en el don de sí. Por eso, Maritain establece un nexo entre donación y existencia de la personalidad, reformulando así el cogito cartesiano:

Pour pouvoir se donner, il faut d'abord exister. ${ }^{5}$

${ }^{3}$ CoRtina, A. (2007), Ética de la razón cordial. Oviedo, Nóbel.

${ }^{4}$ Sobre esto, McCaulfF, C. M. A. (2009), "Cognition and Consensus in the Natural Law Tradition and in Neuroscience: Jacques Maritain and the Universal Declaration of Human Rights", Villanova Law Review $\mathrm{n}^{\circ}$ 54, pp. 435-478.

${ }^{5}$ MARITAIN, J. (1947), La personne et le bien commun, en Oeuvres complètes (1986), Friburgo (Suiza) - París, Saint Paul, p. 191. 
Así, el cogito mariteniano bien podría ser: dono me ipsum, ergo sum; me doy, luego existo. Consideramos que este nexo entre don y existencia es uno de los planteamientos más deslumbrantes del filósofo parisino. Maritain entiende la vocación al amor, y por tanto al don, como constitutiva del ser humano, marcando en esta dirección su sentido último y su horizonte de desarrollo. Por este motivo, existir como persona está indisolublemente unido a vivir la experiencia del amor y del don de sí. Para decirlo claramente, la experiencia del don en tanto que expresión del amor nos constituye como personas. Esta experiencia del don de sí abre al ser humano a una nueva perspectiva de encuentro: la propia del vínculo fraterno. Desde la perspectiva del don y el amor, se percibe a las demás personas como "otros sí mismos":

De telle sorte que [la personne] est en quelque manière un univers à soi-même, un microcosme, dans lequel le grand univers tout entier peut être contenu par la connaissance, et qui par l'amour peut se donner tout entier à des êtres qui sont à lui comme d'autres lui-même. ${ }^{6}$

Llego así a la parte final de mi intervención, que me conduce necesariamente a Caritas in veritate (en adelante CiV). La encíclica propone introducir la lógica del amor en la vida social, política y económica a través de la experiencia sorprendente del don ( ${ }^{\circ} 34$ ); es justo en ella donde Benedicto XVI encuentra una auténtica pedagogía de la fraternidad. El don, como expresión del amor, nos habilita para construir una sociedad fraterna (la ciudad humana en palabras de $\mathrm{CiV}{ }^{\circ} 6$ ), porque el hecho de dar gratuitamente nos permite vivir la experiencia de la apertura y de la responsabilidad por la suerte del otro (aquello que Caín era incapaz de hacer). El texto (capítulo III) llama a vivir desde ese ethos las relaciones económicas, empresariales y laborales para propiciar un cambio de paradigma: desde la lógica del intercambio y la contraprestación hacia un modo de relación basado en el amor. Este cambio de paradigma permitirá al ser humano afrontar un crecimiento más profundo, más humano, que trascienda la codicia y le abra un horizonte de desarrollo integral. ${ }^{7}$

Pero retomemos la expresión utilizada en el $n^{\circ} 34$, donde Benedicto XVI califica la experiencia del don como sorprendente. Seguramente, esta expresión contiene una de las claves de comprensión de la encíclica. La experiencia del don es sorprendente porque es inconcebible para el homo economicus. Es decir,

${ }^{6}$ MARITAIN, J. (1947), op. cit., p. 188.

7 Melé, D. et al. (2010), El desarrollo humano integral: comentarios interdisciplinares a la encíclica Caritas in veritate de Benedicto XVI, Barcelona, Iter. 
aquél cuyo objetivo es el enriquecimiento a ultranza y actúa desde la cerrazón egoísta en servicio exclusivo de sus propios intereses no puede concebir una experiencia de apertura, de gratuidad, de responsabilidad por la suerte del otro, de ob-ligacion con él.

Según la encíclica, frente a la tan extendida concepción de la actividad económica como búsqueda de la utilidad y el provecho propio, el don nos abre a una nueva perspectiva, la de la responsabilidad por el otro, la de la atención a quienes ocupan las posiciones más débiles, la de la búsqueda del bien común a través de la virtud y la amistad que tan bien ilustrara Cicerón; esa relación que, según el senador romano, nos impide resbalar hacia el abismo. Se puede decir que la experiencia del don nos rescata de un ethos que nos limita, nos aísla y convierte a los demás en competidores, y nos abre a una nueva lógica que concibe a los demás como hermanos. Por eso afirma el $n^{\circ} 34$ de CiV que el ser humano está hecho para el don, ya que éste nos habilita para construir la familia humana. Como afirma Zamagni,

sin prácticas extensas de don [...] las personas no serán ayudadas a alcanzar la alegría de vivir. Porque eficacia y justicia, incluso unidas, no bastan para garantizar la felicidad de las personas. ${ }^{8}$

Según CiV (capítulo III), la función propia del don es hacernos comprender que, junto a los bienes de justicia, están los bienes de la gratuidad, y que no es auténticamente humana la sociedad que se contenta únicamente con los bienes de justicia. El don nos hace crecer como personas en un ethos que va más allá de las relaciones de equidad porque nos enraíza en el amor, lo más constitutivamente humano.

En la experiencia del don importa más la relación intersubjetiva que el bien donado. Por eso el don es una expresión del amor que habilita al ser humano para construir una sociedad fraterna (la ciudad humana, en palabras de la encíclica). En ese sentido, para CiV, la ciudad humana no se promueve sólo con relaciones de derechos y deberes sino, antes y más aún, con relaciones de gratuidad, de misericordia y de comunión $\left(n^{\circ} 6\right)$.

Para Zamagni,

el mensaje que CiV nos deja es el de pensar la gratuidad, y por tanto la fraternidad, como claves de la condición humana y, como consecuencia, el de ver en el ejercicio del

${ }^{8}$ ZAMAGNI, S. (2009), "Fraternidad, don y reciprocidad en la Caritas in veritate", Revista Cultura Económica, $\mathrm{n}^{\circ} 75-76$, agosto-diciembre.

Revista de Fomento Social 70 (2015) 
don el requisito indispensable para que Estado y mercado puedan funcionar con la mira en el bien común. ${ }^{9}$

El Papa Benedicto sitúa en la fraternidad todas las esperanzas de construcción de un nuevo orden mundial que posibilite el desarrollo integral y solidario de la humanidad. Tanto es así que las referencias a la construcción de la familia humana son constantes (por ejemplo, al aludir a las posibilidades que ofrece la globalización o a las reflexiones relativas al medio ambiente). Y no hay verdadera fraternidad sin responsabilidad por la suerte del otro. Construir la familia humana significa cimentar la sociedad sobre una profunda convicción solidaria (en el sentido etimológico de conformar un solidum, un único cuerpo; o, en palabras más evangélicas, una comunidad), solidaridad que fue descrita por Juan Pablo II como que todos se sientan responsables de todos. ${ }^{10}$

Para Benedicto XVI, mientras no haya un crecimiento y extensión de la cultura de la fraternidad, no será posible un desarrollo que además de humano sea integral." En la fraternidad es, por tanto, donde la humanidad se juega sus posibilidades de desarrollo integral.

Resumo, para finalizar, las conclusiones principales de esta nota:

1. No es posible entender la lógica del don desde el pensamiento calculador.

2. El don parte del reconocimiento de la dignidad del otro, al que considero "otro yo mismo", con quien me implico.

3. El don implica reciprocidad: todos somos donantes y donatarios, lo que nos remite a la dignidad de todos, ya que todos tenemos algo que ofrecer.

4. El don es transitivo: se espera que el donatario done, no necesariamente al donante, sino también a cualquier otro.

5. La lógica del don no busca la equivalencia económica en el valor de lo donado y lo recibido.

\footnotetext{
9 ZAMAGNI, S. (2009), "Fraternidad, don y reciprocidad en la Caritas in veritate", Revista Cultura Económica, $\mathrm{n}^{\circ} 75-76$, agosto-diciembre 2009, p. 6.

10 Sollicitudo rei socialis, $n^{\circ} 38$, citada por MARGenat, J. M. (2009), "La fraternidad, camino para la familia humana", Dossier Caritas in Veritate, Revista de Fomento Social n 64, p. 733.

11 Margenat, J. M. (2009), art. cit., 734.
} 
6. El don es consustancial a la persona y le ofrece una pedagogía privilegiada para crecer en el amor, que es lo esencialmente y genuinamente humano. Dar es ser persona.

Termino con una cita - de nuevo- de la Ética de la razón cordial de Adela Cortina:

Quien hace la experiencia del reconocimiento recíproco, la experiencia con otro ser humano que es carne de la propia carne y hueso del propio hueso, no sólo se siente exigido a dar al otro "lo que le corresponde" como persona, sino que se siente urgido a compartir con él lo que ambos necesitan para ser felices. Más allá del derecho y el deber se abre el amplio misterio de la obligación, el prodigioso descubrimiento de que estamos ligados unos a otros de forma indisoluble y, por tanto, ob-ligados, aun sin sanciones externas, sino desde lo hondo. Es en lo profundo donde se descubre esa ligadura profunda, el secreto de la felicidad. De ella brota el mundo de las obligaciones que no pueden exigirse, sino compartirse graciosamente, el mundo del don y del regalo, del consuelo en tiempos de tristeza, del apoyo en tiempos de desgracia, de la esperanza cuando el horizonte parece borrarse, del sentido ante la experiencia del absurdo. Esos bienes los comparten quienes los regalan, no por deber, sino por abundancia del corazón. Mas allá del derecho y el deber se abre el amplio misterio de la gratuidad, el prodigioso descubrimiento del vínculo que une a los seres humanos y es, por lo mismo, fuente de ob-ligatio, de obligación sentida y querida, no impuesta. ${ }^{12}$

${ }^{12}$ CoRtINA, A., op. cit. 